\title{
Seven years of blue and fin whale call abundance in the Southern California Bight
}

\author{
Ana Širović ${ }^{1, *}$, Ally Rice ${ }^{1}$, Emily Chou ${ }^{1}$, John A. Hildebrand ${ }^{1}$, Sean M. Wiggins ${ }^{1}$, \\ Marie A. Roch ${ }^{2}$
}

${ }^{1}$ Scripps Institution of Oceanography, University of California San Diego, La Jolla, California 92093-0205, USA

${ }^{2}$ San Diego State University, San Diego, California 92182-7720, USA

\begin{abstract}
Blue whales Balaenoptera musculus and fin whales B. physalus are common inhabitants of the Southern California Bight (SCB), but little is known about the spatial and temporal variability of their use of this area. To study their distribution in the $\mathrm{SCB}$, high-frequency acoustic recording packages were intermittently deployed at 16 locations across the SCB from 2006 to 2012. Presence of blue whale B calls and fin whale $20 \mathrm{~Hz}$ calls was determined using 2 types of automatic detection methods, i.e. spectrogram correlation and acoustic energy detection, respectively. Blue whale B calls were generally detected between June and January, with a peak in September, with an overall total of over 3 million detections. Fin whale $20 \mathrm{~Hz}$ calls, measured via the fin whale call index, were present year-round, with the highest values between September and December, with a peak in November. Blue whale calls were more common at coastal sites and near the northern Channel Islands, while the fin whale call index was highest in the central and southern areas of the $\mathrm{SCB}$, indicating a possible difference in habitat preferences of the 2 species in this area. Across years, a peak in blue whale call detections occurred in 2008, with minima in 2006 and 2007, but there was no long-term trend. There was an increase in the fin whale call index during this period. These trends are consistent with visual survey estimates for both species in Southern California, providing evidence that passive acoustics can be a powerful tool to monitor population trends for these endangered species.
\end{abstract}

KEY WORDS: Blue whales · Fin whales · Acoustic monitoring · Southern California Bight

\section{INTRODUCTION}

Blue whales Balaenoptera musculus and fin whales B. physalus are the 2 largest cetacean species and as such, they were major targets of the whaling industry, which led to tremendous declines in their populations during the 20th century. It is estimated that their populations were depleted by more than $70 \%$, possibly by as much as $90 \%$ for blue whales, resulting in an Endangered listing by the IUCN (Reilly et al. 2008, 2013). While commercial whaling is no longer a threat to these populations, a number of other threats still exist, including ship strikes (Redfern et al. 2013, Irvine et al. 2014), disturbance from ships

\footnotetext{
*Corresponding author: asirovic@ucsd.edu
}

and other anthropogenic noise sources (Melcón et al. 2012), and possibly entanglement or by-catch (Cole et al. 2006, Pace et al. 2014). Generally, these threats are lower for pelagic species, but they increase when the animals are found in areas with increased human activity (Reilly et al. 2008).

The Southern California Bight (SCB) is an area of very high human use that is also a highly productive ecosystem due to strong upwelling (Smith \& Eppley 1982). This productivity attracts a variety of cetaceans, including blue and fin whales (Barlow \& Forney 2007). Blue whales are present in the SCB primarily during the summer and fall as this is an important foraging area for the species, and they migrate out of the

() The authors 2015. Open Access under Creative Commons by Attribution Licence. Use, distribution and reproduction are unrestricted. Authors and original publication must be credited. Publisher: Inter-Research · www.int-res.com 
area at the start of winter (Fiedler et al. 1998, Burtenshaw et al. 2004). Some variation in blue whale distribution and migration routes may exist from year to year, likely a result of environmental variations, such as those in prey availability (Bailey et al. 2009). Fin whales, in contrast, are present in the SCB yearround, with peak numbers in late summer and early fall (Barlow 1995, Forney et al. 1995, Forney \& Barlow 1998, Oleson 2005, Širović et al. 2013). It is not clear whether this continuous presence is a result of a resident population, a rotating migration through the $\mathrm{SCB}$, or a combination of the two. Given the substantial use of the SCB by the 2 species, understanding their long-term trends is an important first step for the study of the potential impacts of human activity in this region on these endangered species.

Blue and fin whales produce low-frequency, stereotypic sounds that are well suited for passive acoustic monitoring and automatic detection (Watkins 1981, Rivers 1997, Širović et al. 2004). Blue whales in the SCB produce 3 call types, consistent with the calls recorded across the Northeast Pacific (McDonald et al. 2006). The 'A call' consists of a relatively long (up to $20 \mathrm{~s}$ ) series of rapid, low-frequency pulses. The 'B call' often follows the A call and is a long ( $\geq 10 \mathrm{~s}$ ) tonal call with a downsweep in frequency (Thompson et al. 1996, Rivers 1997). Co-occurring sequences of $A B$ calls are referred to as song and are believed to serve a reproductive function (McDonald et al. 2001, Oleson et al. 2007a). The third call type, the 'D call', is much more variable in frequency and temporal characteristics and repetition patterns and is believed to serve a social function (McDonald et al. 2001, Oleson et al. 2007a). Fin whales produce at least 2 call types, '20 Hz' and '40 Hz' calls. Both call types are $1 \mathrm{~s}$ long downswept pulses, with $20 \mathrm{~Hz}$ calls sweeping in frequency from 23 to $18 \mathrm{~Hz}$ (Watkins 1981, Watkins et al. 1987) and $40 \mathrm{~Hz}$ calls sweeping from 62 to $48 \mathrm{~Hz}$ (Širović et al. 2013). These calls can be produced in regular and irregular sequences (Watkins et al. 1987), with regular sequences, i.e. songs, attributed to males (Watkins et al. 1987, Croll et al. 2002).

Long-term passive acoustic monitoring can be used to gain a better understanding of baleen whale distribution and migration patterns (Watkins et al. 2000, Burtenshaw et al. 2004). Blue whale calls have been recorded in the SCB from April to January, with D calls occurring until November, and A and B calls recorded from June to January (Oleson et al. 2007b). Visual surveys indicate that lower densities of blue whales occur in offshore waters during the summer and fall (Barlow \& Forney 2007, Becker et al. 2010). Fin whale $20 \mathrm{~Hz}$ calls have been detected year-round in the SCB (Oleson 2005, Širović et al. 2013). Recent visual surveys suggest that fin whales use nearshore waters in the winter and spring and shift to offshore waters in the summer and fall (Douglas et al. 2014). In this work, we present results from $7 \mathrm{yr}$ of recordings at 16 sites across the SCB to provide the first extensive overview of the seasonal and interannual variation, as well as the first details on the spatial variability in the distribution of calling blue and fin whales across this region.

\section{MATERIALS AND METHODS}

\section{Data acquisition}

To provide long-term recordings of cetacean sounds, high-frequency acoustic recording packages (HARPs) were intermittently deployed at 16 locations across the SCB between 2006 and 2012 (Fig. 1). At each site, recording effort varied over time, with the shortest

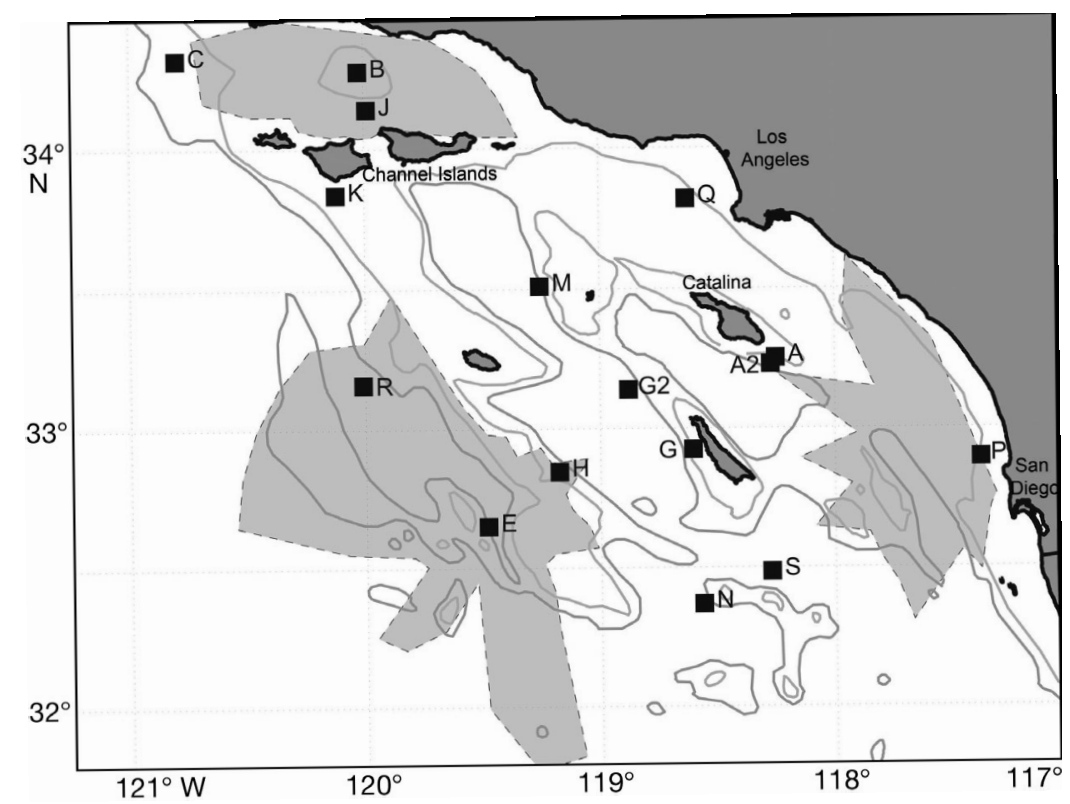

Fig. 1. Locations of high-frequency acoustic recording package (HARP) deployment sites (uppercase letters; see Table S1 in the Supplement at www.intres.com/articles/suppl/n028p061_supp.pdf) in the Southern California Bight. Examples of detection areas for blue whale calls obtained by propagation modeling are shown for Sites B, E, and P as grey shaded areas within a broken line. Grey lines mark 500 and $1000 \mathrm{~m}$ bathymetry contours 
coverage of approximately 6 mo at Site $\mathrm{K}$, to nearly 4 yr of data at Sites B and C (see Table S1 in the Supplement at www.int-res.com/articles/suppl/n028 p061_supp.pdf). HARPs are calibrated acoustic recorders consisting of a hydrophone, data logger, acoustic releases, flotation, and batteries capable of long-term (3-12 mo) deployments (Wiggins \& Hildebrand 2007). Data were sampled by HARPs at $200 \mathrm{kHz}$, except 2 deployments at Site $C$ that were sampled at $320 \mathrm{kHz}$, but before any analyses were conducted, all data were decimated by a factor of 100 to create effective bandwidth from 10 to $1000 \mathrm{~Hz}$ (for $200 \mathrm{kHz}$ sampled data) or 10 to $1600 \mathrm{~Hz}$ (for $320 \mathrm{kHz}$ sampled data), respectively. In the next step of data processing, long-term spectral averages (LTSAs) with $5 \mathrm{~s}$ temporal and $1 \mathrm{~Hz}$ frequency resolution were created. Full versions of data in the waveform audio format as well as LTSAs were available for subsequent processing. Blue whale B calls and fin whale $20 \mathrm{~Hz}$ calls were automatically detected from these data.

\section{Call detection}

\section{Blue whales}

Blue whale B calls were automatically detected using spectrogram correlation (Mellinger \& Clark 2000). This method cross-correlates a time-frequency kernel representation of a call with a spectrogram of the recording; a detection event occurs when the correlation value exceeds the specified threshold for a specified duration, in the case of our detector, $5 \mathrm{~s}$. Since they generally occur in repeated sequences, the presence of B calls is also a good proxy for the presence of blue whale A calls (Oleson et al. 2007b).

Spectrogram correlation can be used successfully for blue whale B calls due to their stereotypic frequency and temporal characteristics (Rivers 1997). However, the performance of the automatic detector is affected by seasonal and interannual shifts in call frequency (McDonald et al. 2009) and seasonal changes in call abundance (A. Širović unpubl. data). To account for these changes and keep rates of missed and false calls as constant as possible, multiple kernels and thresholds were used for each year and site with data as described below.

Kernels were developed for June and October for each year of data to account for the variation in call frequency content between the start (June) and peak (October) of the calling season. The kernels were calculated from an average of approximately 30 good quality B calls that were each separated by at least
$24 \mathrm{~h}$ to ensure that the calls were not representative of a single animal. The peak frequency of the third harmonic of the calls was measured automatically at 5 time periods of the call $(0,1.5,3,4.5$, and $10 \mathrm{~s})$ using specially adapted MATLAB-based software (Fig. 2). To the maximum extent practicable, the kernels measured from June calls were applied to recordings from April to September, and the kernels measured from October calls were applied to recordings from October to March of the following year.

A reliable automatic detector should have high precision and recall values, meaning it should produce a limited number of false and missed calls. To optimize those values across all deployments, thresholds were determined for June, October, and December each year. Ground truth detections were developed for these months by manually picking 200 calls in June and December, when call abundance is lower, and 400 calls in October, at peak call abundance. The optimal threshold was manually chosen based on the highest precision and recall values. There was a substantial level of variation in precision and recall values across and within sites (Fig. 3), and the most pronounced across-site variability (e.g. between Sites M and N and Sites A and G2) was a combined result of difference in background noise characteristics and analysis by different analysts (A. Širović unpubl. data).

An automatic detector was run on WAV files from each deployment using the appropriate kernel and threshold. For the months when blue whales are not commonly present in Southern California (February to May), the automatic detections were manually checked and all false calls were eliminated from subsequent analyses. All detections were stored in the Tethys metadata database (Roch et al. 2013), including metadata information describing the kernel parameters, detection threshold, deployment information, name of the original WAV file, and time of the detection event.

Fin whales

In some regions, fin whale $20 \mathrm{~Hz}$ calls can be so abundant that a constant band of noise across the bandwidth of their calls is created, making it difficult to detect individual calls (Watkins et al. 2000, Širović et al. 2004). In those cases, an energy detector (i.e. fin whale call index) is the most suitable method for detecting the presence of calling fin whales (Širović et al. 2004, Nieukirk et al. 2012). The SCB is a region with a seasonally present 'fin whale noise band'. For 


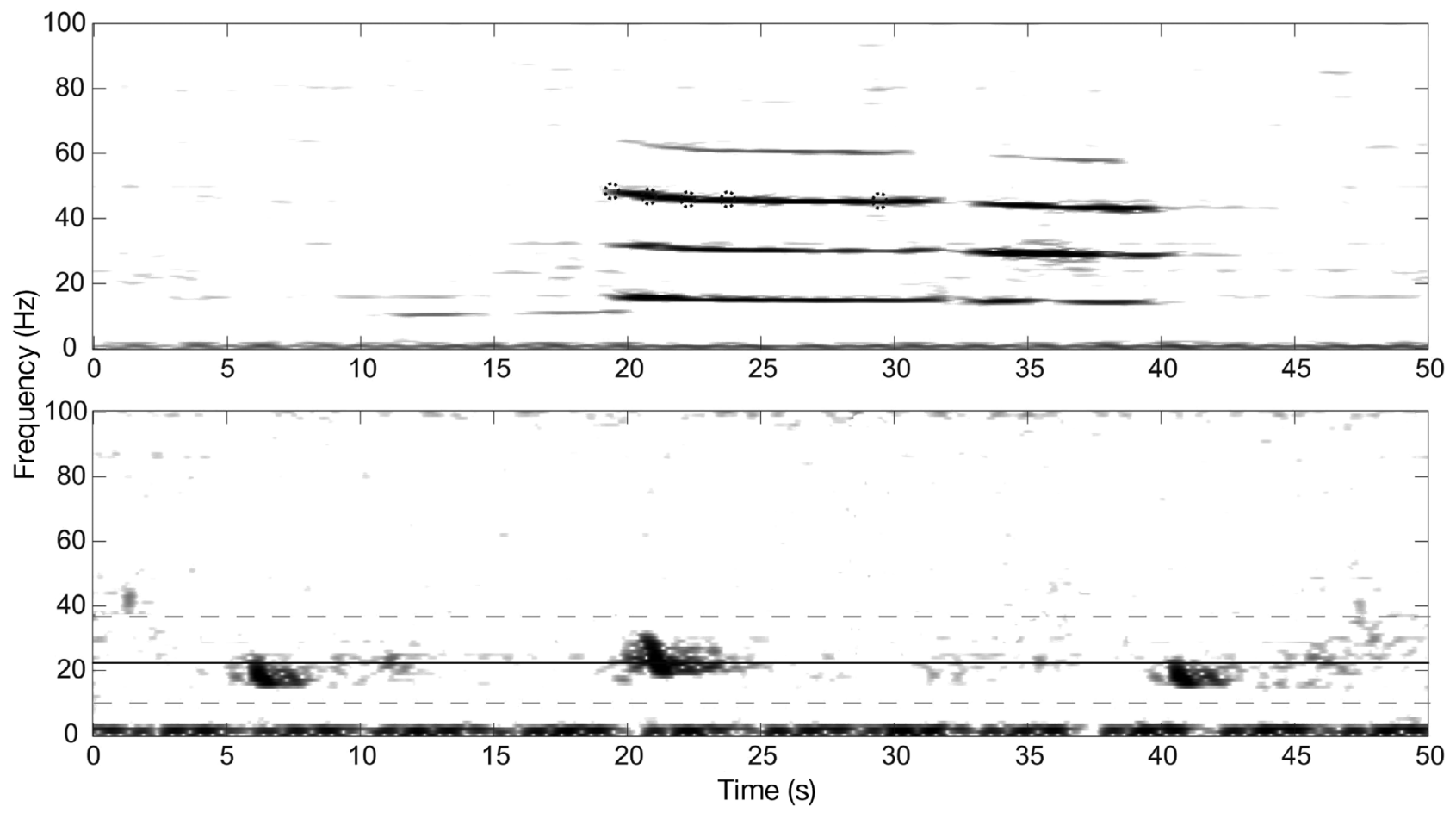

Fig. 2. Example spectrograms of blue whale (Balaenoptera musculus) B calls (top) recorded on 10 September 2010 ( $2 \mathrm{~s}$ analysis window, $95 \%$ overlap, Hann window) and fin whale $20 \mathrm{~Hz}$ calls (bottom) recorded on 9 October 2010 (1 s analysis window, $95 \%$ overlap, Hann window). Both recordings were made at Site M (see Fig. 1). Dotted circles on the blue whale B call mark locations where frequency was extracted for kernel creation. Lines on the fin whale spectrogram show frequency bands used for calculating the fin whale call index, with the solid black line at $22 \mathrm{~Hz}$ marking the fin whale (signal) band and dashed grey lines marking noise bands used to evaluate background noise

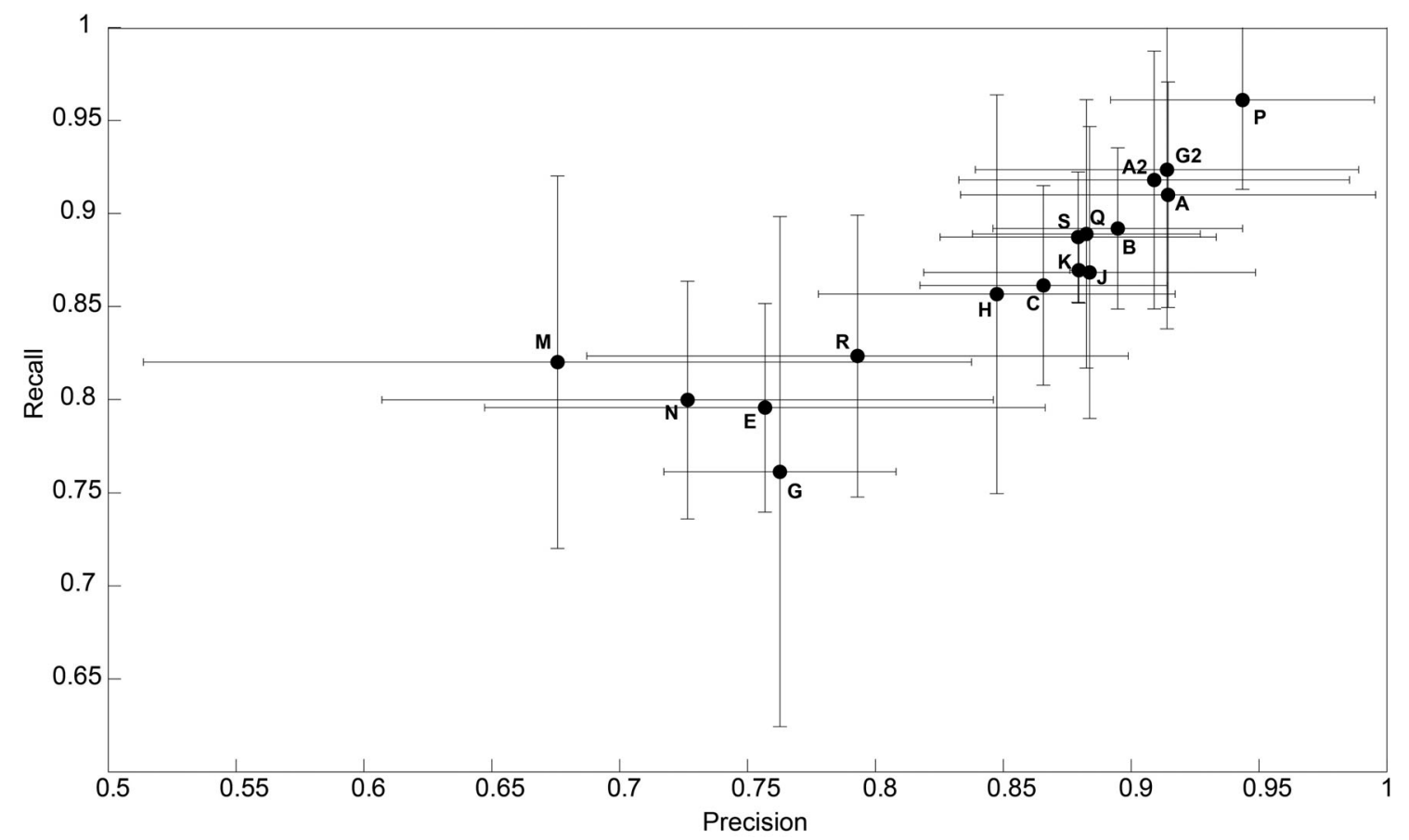

Fig. 3. Mean values $( \pm \mathrm{SE})$ of precision and recall for the blue whale (Balaenoptera musculus) $\mathrm{B}$ call detector for each site $(\mathrm{N}=3)$. See Fig. 1 for site locations 
the present study, the fin whale call index was calculated as the calibrated signal to noise ratio at $22 \mathrm{~Hz}$. The noise estimate was the linear average of acoustic power at 10 and $34 \mathrm{~Hz}$ (Fig. 2). The calculations were conducted using LTSAs, so initial values were based on $5 \mathrm{~s}$ averages, but to obtain a daily fin whale call index, these values were further averaged across each deployment day.

All fin whale call index values were stored in the Tethys database (Roch et al. 2013). In addition to the day of detection and call index value, each entry also included metadata on the energy detector used (namely, frequencies used for calculation of signal and noise), the name of the LTSA file used for the calculation and its frequency and temporal resolution, and deployment information.

\section{Detection range calculations}

To meaningfully compare detections from different sites, it is necessary to understand the variability in the detection range across sites (Helble et al. 2013a). We calculated transmission loss (TL) models for blue whale B calls and fin whale $20 \mathrm{~Hz}$ calls at each site using the Effects of Sound on Marine Environment (ESME) 2012 Workbench framework (D. Mountain, Boston University; http://esme.bu.edu). Sound propagation models were developed using a Rangedependent Acoustic Model (RAM) simulator, which models acoustic propagation using an iterative parabolic equation solver. This model is better suited for low-frequency sounds, such as those from baleen whales, than the alternative Bellhop model. For both species, we developed models using environmental data sources available in ESME, which were obtained from the Oceanographic and Atmospheric Master Library. We used Surface Marine Gridded Climatology wind speed data with $60 \min (111 \mathrm{~km})$ resolution and Generalized Digital Environment Model v. 3.0 data for water temperature and water salinity, which was used to calculate sound speed profiles at $15 \mathrm{~min}(27.8 \mathrm{~km})$ resolution. Sediment data (bottom sediment type) had $5 \mathrm{~min}(9.26 \mathrm{~km})$ resolution and bathymetry from the Digital Bathymetry Database v. 5.4 had $0.5 \mathrm{~min}(926 \mathrm{~m})$ resolution.

Initially, we tested differences in propagation characteristics across the year by comparing propagation models for January, April, July, and October at Site G. Since there was little variation across those months (less than $4 \mathrm{~dB}$ difference in TL over $100 \mathrm{~km}$ across months), we developed models for each deployment site for October, as that was the time period with the most common presence of these 2 species and it was also the month which differed least from other months in terms of TL $(<2.5 \mathrm{~dB})$. The goal was to be able to compare blue whale call detection counts and fin whale call index values across sites, so we applied these models to data across the year, with the underlying assumption that there was a similar level of variability across the year among sites.

To calculate detection area for each deployment and call type, we ran propagation models for all sites using different settings for blue and fin whale calls. For blue whale B calls, we ran the propagation model for $46 \mathrm{~Hz}$, assuming call source level (SL) $186 \mathrm{~dB}$ re: $1 \mu \mathrm{Pa} @ 1 \mathrm{~m}$ (McDonald et al. 2001). For fin whales, the model was run for $22 \mathrm{~Hz}$ and call SL $189 \mathrm{~dB}$ re: $1 \mu \mathrm{Pa} @ 1 \mathrm{~m}$ (Weirathmueller et al. 2013), adjusted for average $5 \mathrm{~Hz}$ bandwidth of fin whale calls (Watkins 1981, Watkins et al. 1987). In both cases, we assumed a whale calling depth of $30 \mathrm{~m}$ (Oleson et al. 2007a). The models were run along 32 individual, $100 \mathrm{~km}$ long radials centered at each HARP deployment location. To estimate the detection range for each radial, we needed to determine the total possible TL. This total possible TL was calculated as the difference between the call SL and background noise at that site, minus the detectability of the sound. We calculated the average background noise level (in $1 \mathrm{~Hz}$ bins) at each site during all Octobers with recordings and used the interpolated value of noise at $46 \mathrm{~Hz}$ and $22 \mathrm{~Hz}$ from adjacent bins (to remove the increase in energy due to blue and fin whale calling presence). We used $2 \mathrm{~dB}$ as the detectability level for the spectrogram correlation detector, and $0 \mathrm{~dB}$ for energy detection. Therefore, the detection range along each radial was determined as the range at which the TL from the RAM acoustic simulator became less than the total possible TL calculated from the SL, background noise, and detectability. The total detection area at a deployment site was then calculated as the area of the polygon (see examples in Fig. 1) described by the maximum detection ranges along each of the 32 radials (Table $\mathrm{S} 1$ ).

For blue whales, total call detection counts for each site were normalized by this detection area to allow for comparison among sites. For fin whales, the fin whale call index was normalized by dividing by a factor that accounts for both the area and TL:

$$
\sum_{j=1}^{32} \sum_{i=1}^{N} \frac{A_{i j}}{T L_{i j}}
$$

where $N$ is the total number of propagation steps calculated along a radial, $A_{i}$ is a detection area (in $\mathrm{m}^{2}$ ) within each step of a radial, and $T L_{i}$ is the modeled 
TL (in $\mathrm{dB}$ ) in that area, with summing over all the radials $(j)$. Since fin whale call abundance was measured as an acoustic energy ratio, rather than a simple call count, the additional step of using TL was necessary to account for fine-scale differences in propagation. Normalizing by TL-area as described accounts for differences in, for example, a propagation model with maximum detection range of $50 \mathrm{~km}$ where most of the TL occurs in the first $10 \mathrm{~km}$ versus a model where over the same range of $50 \mathrm{~km}$, TL decreases gradually. Without this normalization, each of these 2 propagation scenarios would result in very different levels of fin whale call index for the same number of calls produced at different places along the propagation path.

\section{Trend analyses}

To evaluate the overall seasonal and interannual trends in the abundance of blue whale and fin whale calling across sites, we calculated the overall monthly and annual mean daily blue whale call detection rate and daily fin whale call index, normalizing by the appropriate recording effort in each case. All available data were used for seasonal analysis. For interannual analysis, we only used data from Sites B, C, and $\mathrm{H}$, which had the longest continuous time series and represent potentially different SCB habitats (northern Channel Islands, California Current, and southern SCB, respectively). The seasonal trend was removed from the daily interannual data by performing multiplicative seasonal adjustment to eliminate the potential variability due to time of sampling. This adjustment was performed by dividing each time series value by a monthly index number, which represents a fraction of the overall annual median typically observed in that month. We tested for overall trends in year-to-year detections and call index using the Mann-Kendall monotonic trend test at an $\alpha$-level of 0.05 . When the trend was found to be significant, we estimated Sen's slope and report it along with its confidence intervals.

Our data also allowed us to investigate spatial trends in the distribution of calling animals. Thus, to evaluate seasonal variability in spatial use of the SCB, we plotted the monthly averages across all sites and years where data were available for daily blue whale call detections and fin whale call indices. To investigate interannual spatial patterns, we first normalized all site-specific daily data by removing the appropriate overall monthly mean. We then plotted the annual average of de-meaned values. This allowed us to com- pare relative presence of calling animals at each site in each year relative to overall means. In all calculations, all values were normalized by detection area or TL-area, as appropriate, to obtain values that are comparable across all sites.

\section{RESULTS}

A total of 3152448 blue whale calls were detected at 16 sites during 9404 d (nearly 26 cumulative years) of effort, although some calls may have been detected on more than one instrument. Blue whale B calls were generally detected between June and January, with a peak in September (Fig. 4). Across the years, detections were generally consistent, with a slight peak in 2008, and minima in 2006 and 2007 (Fig. 4B). Blue whale call detections showed no monotonic interannual trend (Mann-Kendall $\tau_{\mathrm{b}}=0.238, \mathrm{p}=0.548$ ).

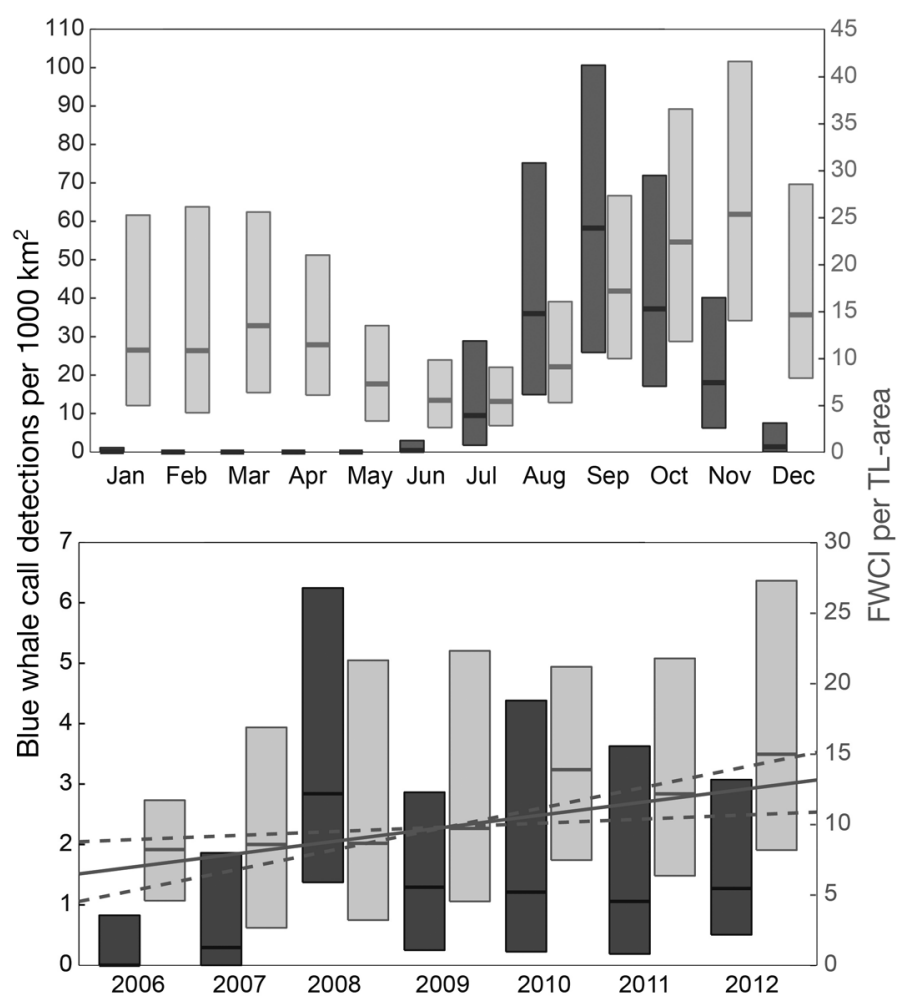

Fig. 4. Overall monthly seasonal (top) and yearly interannual (bottom) pattern of average blue whale (Balaenoptera musculus) B call daily detections normalized by detection area (dark grey) and daily fin whale (Balaenoptera physalus) call index (FWCI) normalized by transmission loss (TL)-area (light grey). Boxplots show median (line within the box) and first and third quartiles of calculated values. All data were also normalized by recording effort. Grey lines show Sen's slope (solid line) with 95\% confidence intervals (broken lines) for interannual trend in fin whale call index over the years 
The fin whale $20 \mathrm{~Hz}$ call index was greater than 0 , indicating some likely presence of fin whales producing $20 \mathrm{~Hz}$ calls on $99.8 \%$ of days with recordings. The fin whale call index was above 0 year-round, and the highest values occurred between September and December, with a peak in November (Fig. 4). There was a secondary, smaller peak in the fin whale call index in March. Across the years of this study, there was a positive trend in the fin whale call index (Mann-Kendall $\tau_{\mathrm{b}}=0.905, \mathrm{p}=0.007$ ), with a Sen's slope of 1.126 (CI: 0.356-1.788; Fig. 4).

\section{Blue whale B call abundance}

Notwithstanding overall seasonal patterns, the spatial and temporal distribution of blue whale B call detections varied across sites and years (Fig. 5). Generally, sites around the northern Channel Islands, particularly to the north in the Santa Barbara Channel, had the highest call abundances during peak calling periods, but blue whale B calls were also common along more coastal sites near Los Angeles and San Diego (Fig. 6). There may be a preference for Channel Islands sites earlier in the calling season, while later in the season call distribution is more even across the SCB.

The highest calling anomaly occurred in 2008 in the Santa Barbara Channel, where a very high number of blue whale B calls were detected (Fig. 7). In contrast, 2006, 2009, and 2012 had low call detections at those sites, while offshore detections were about average. In 2007 and 2010, offshore sites had call detection rates lower than average, while in 2011, the distribution of callers across the SCB was just about average, although these trends may be somewhat biased by the very large anomaly in the Santa Barbara Channel in 2008 (Fig. 7).

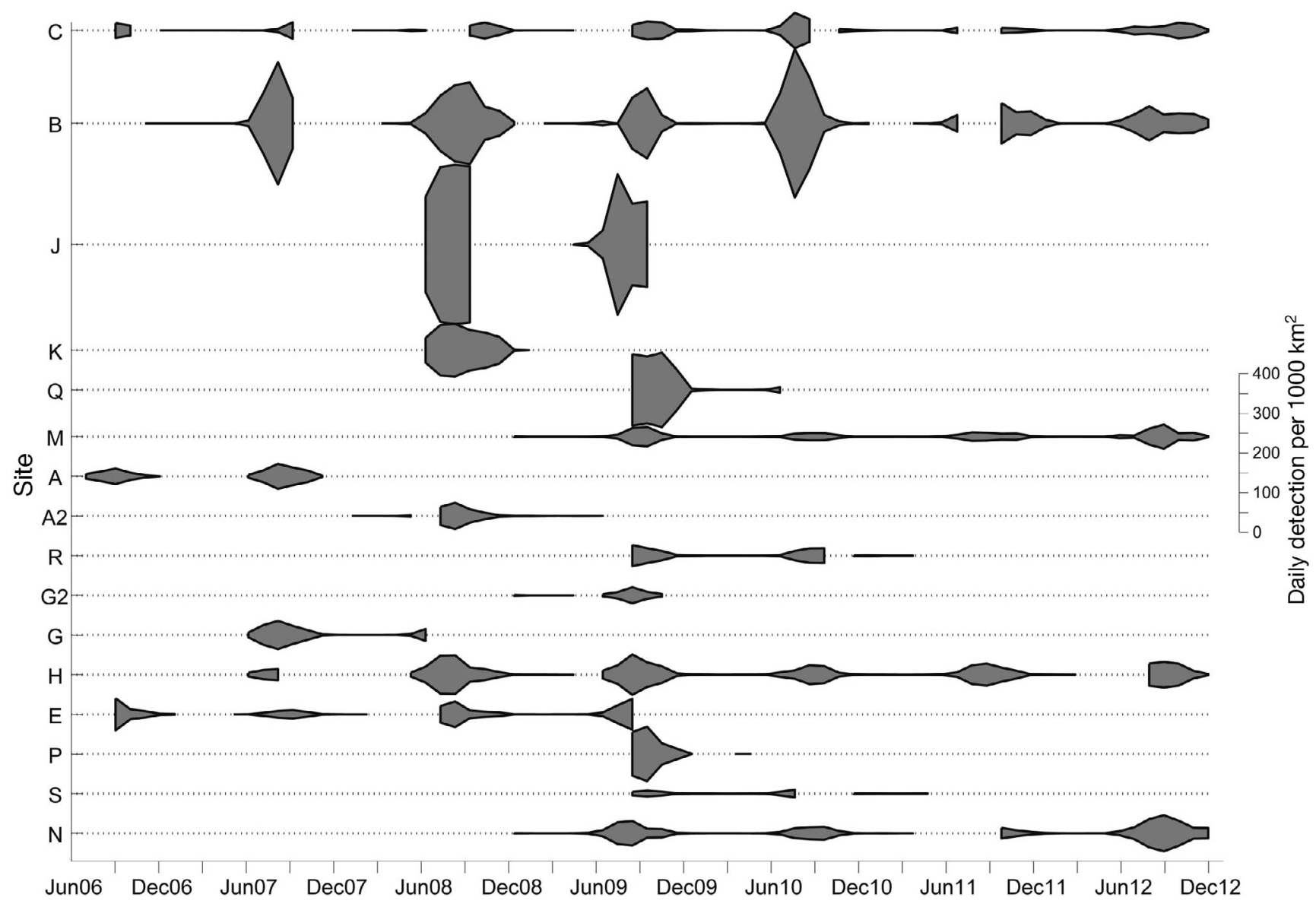

Fig. 5. Monthly averaged daily blue whale (Balaenoptera musculus) B call detection rates at each site in the Southern California Bight. Sites are arranged, to the maximum extent possible, from the northernmost sites at the top towards the southernmost sites at the bottom. Size of the patch represents the daily call detection rate normalized by recording effort and the detection area (see scale). Dotted lines are periods with no data at that site and solid lines denote periods with recording but no detected calls 


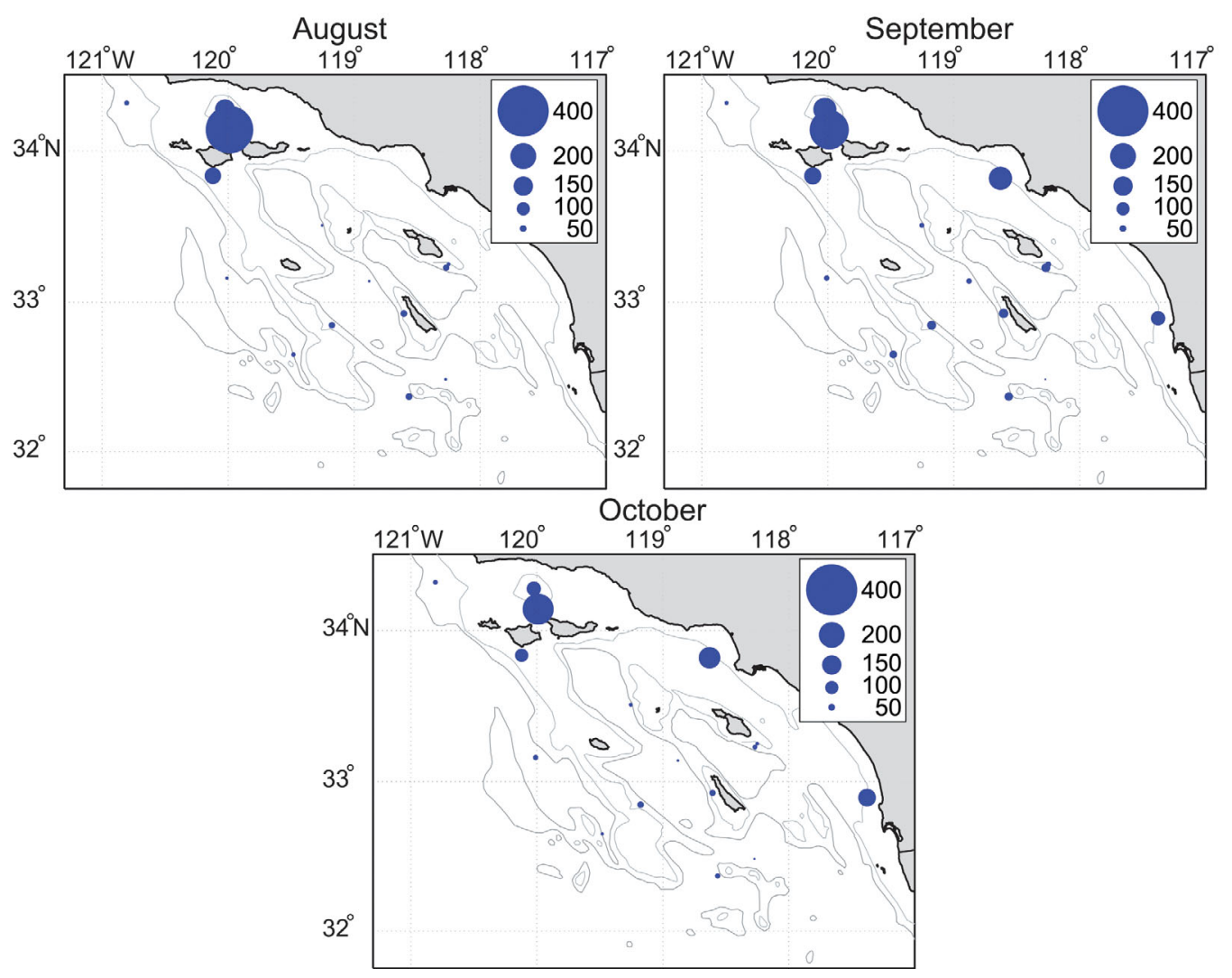

Fig. 6. Spatial distribution of blue whale (Balaenoptera musculus) B call detections across the Southern California Bight during peak calling months. Size of the circle represents average daily B call detection rate normalized by recording effort and detection area during a given month at that site across all years with data. Grey lines mark 500 and 1000 m bathymetry contours

\section{Fin whale abundance based on call index}

The seasonal cycle was less pronounced for the fin whale call index, but there was also a large amount of spatial variability (Fig. 8). The fin whale call index was the highest farther offshore and farther south during peak calling periods (Fig. 9) than peak blue whale call detections, with the highest levels in the basin just to the west of San Clemente Island. One exception was the peak in the fin whale call index at coastal site $\mathrm{Q}$ in December during the one year with data from that site (2009).

Peak call index values were recorded at offshore sites in the central SCB and especially during 2008, 2009, and 2012 (Fig. 10). In 2012, however, a relatively high call index was also recorded at the northern sites in the Santa Barbara Channel. Two years, 2006 and 2011, had a low fin whale call index across most sites, while in 2010 the fin whale call index was low at sites in the central SCB, but it was just above average at the 2 sites at the western edge of the SCB (Fig. 10).

\section{DISCUSSION}

This study offers a first detailed view into the spatial use of the entire SCB region by calling blue and fin whales. The spatial distribution of the 2 species was different, with blue whales detected more commonly at the coastal sites and near the northern Channel Islands, while the fin whale call index was highest in the central and southern $\mathrm{SCB}$, indicating a potential difference in habitat preferences by these 2 species. Our inclusion of propagation models to normalize calling rates by the detection area is novel and unprecedented at this scale, and while it still provides only a general idea of the detection range (see 'Data biases' below for more details), this approach is imperative for providing truly comparable results.

Seasonally, blue whale B calls were detected mostly during the summer and fall, and the fin whale call index indicated year-round presence, but peaking in late fall, both consistent with previous findings across the larger areas of the North Pacific (Watkins et al. 


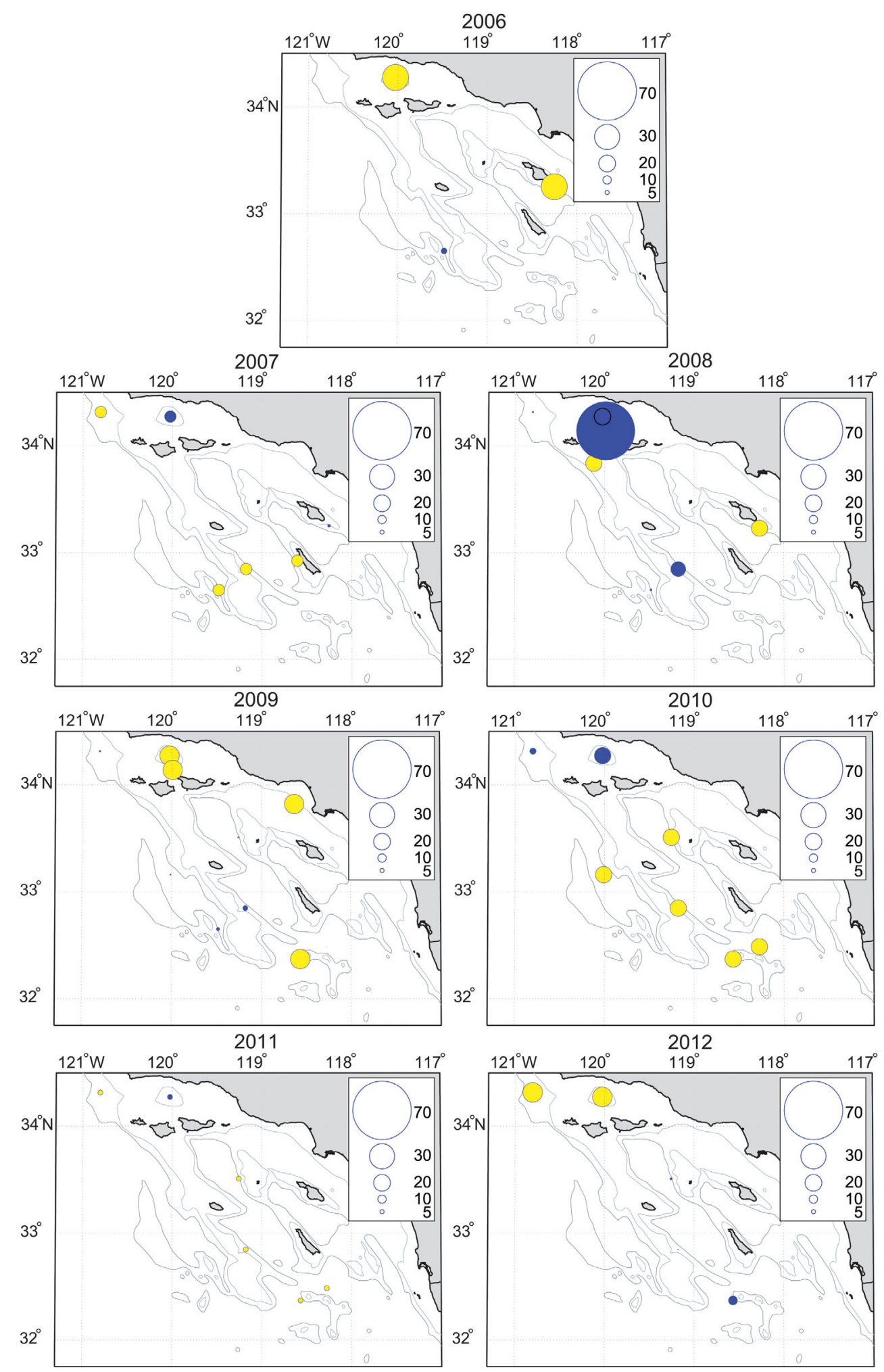

Fig. 7. Variation in the spatial distribution of blue whale (Balaenoptera musculus) B call detections across years in the Southern California Bight. Size of the circle represents mean annual difference (blue whale B call detections per day) from the average Southern California blue whale B daily call detection rates for the appropriate month during this study. Yellow circles represent years with lower than average detections and blue higher than average. All values are normalized by recording effort and detection area. Grey lines mark 500 and 1000 m bathymetry contours; smaller black outlined circle denotes additional data point with less calling presence than the neighboring site 


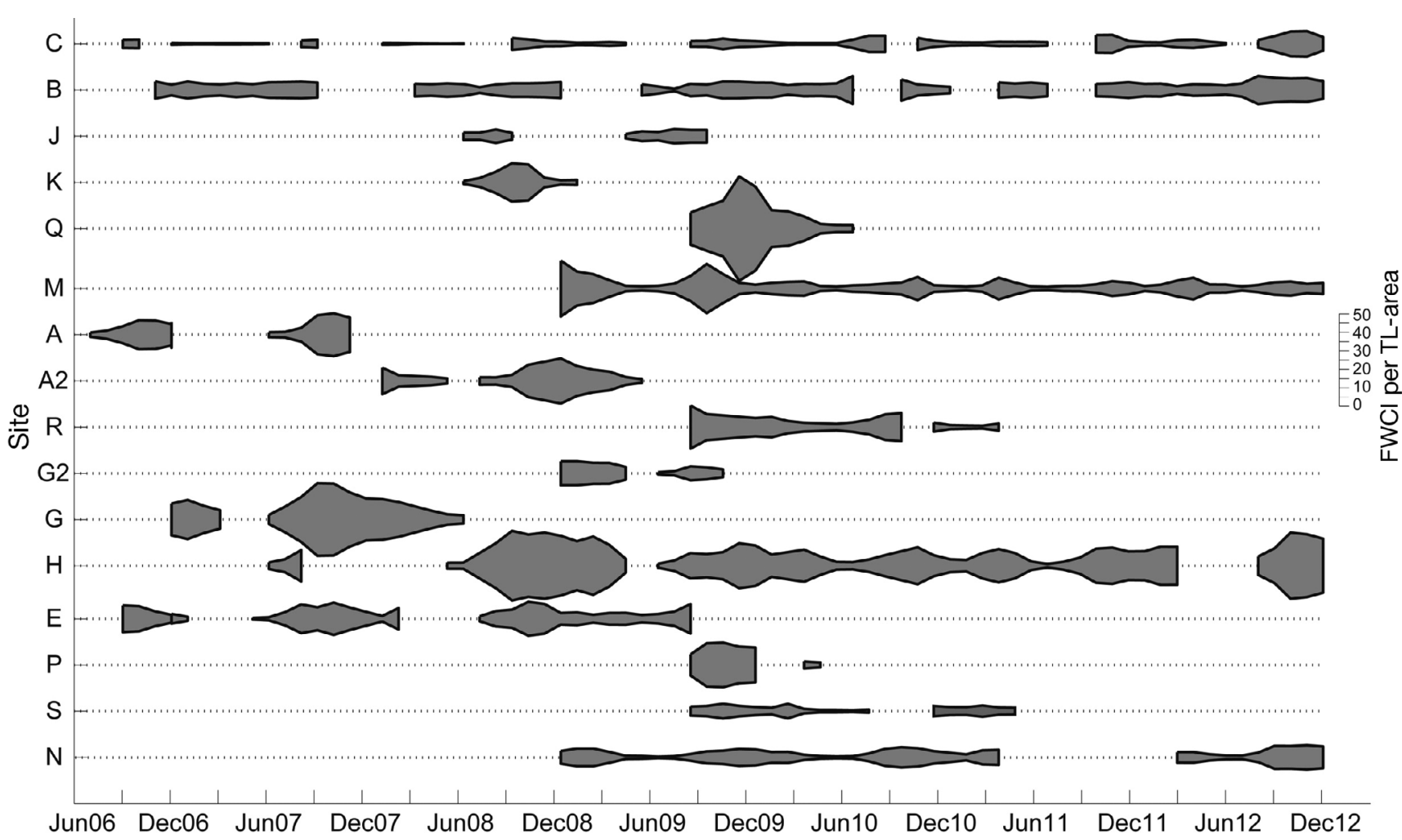

Fig. 8. Monthly averaged daily fin whale (Balaenoptera physalus) call index (FWCI) at each site in the Southern California Bight. Sites are arranged, to the maximum extent possible, from the northernmost sites at the top towards the southernmost sites at the bottom. Size of the patch represents the call index value with periods that appear as straight lines denoting low fin whale call index value (see scale). Dotted lines are periods with no data at that site. All values are normalized by recording effort and transmission loss (TL)-area

2000, Oleson 2005, Stafford et al. 2009). Overall, both species' calls were common in the SCB during the period of our study; blue whale call rates were relatively constant across years despite a slight peak in 2008, while fin whale call index increased during this study. These trends are consistent with visual survey estimates for both species in Southern California (Campbell et al. 2015), thus providing evidence that passive acoustic monitoring of blue and fin whale calls can be a powerful tool for monitoring population trends of these species. While a combination of methods and data is necessary for absolute density estimation (Barlow \& Taylor 2005, Marques et al. 2009), analysis of trends is also informative for population monitoring of endangered species and in this case was accomplished using only passive acoustic methods.

\section{Spatial and seasonal trends in blue and fin whale calling abundance}

This study provides the first SCB-scale spatial view on the presence of calling blue and fin whales. While both species co-occur on small scales (individual site), our study indicates that there may be some degree of larger-scale spatial separation, with calling blue whales preferring coastal areas and areas near islands, and calling fin whales found in southern and southeastern parts of the SCB. Seasonal offshore movement in fin whales indicated from visual survey data (Douglas et al. 2014) was not apparent in the acoustic record, as fin whales were commonly detected coastally already during the fall. The spatial separation between species could stem from different prey preferences (Kawamura 1980). A study including concurrent sampling for blue and fin whales and their prey would shed light on the importance of prey as a driver of the variation in the distribution of these 2 species in the SCB and could help explain some of the spatial variability observed during our studies.

A previous long-term study of blue and fin whale calling presence in the SCB was focused on a much smaller area, largely in the southwest corner of the bight (Oleson 2005). Those data, collected from 2000 to 2003, show largely similar timing in the occurrence 


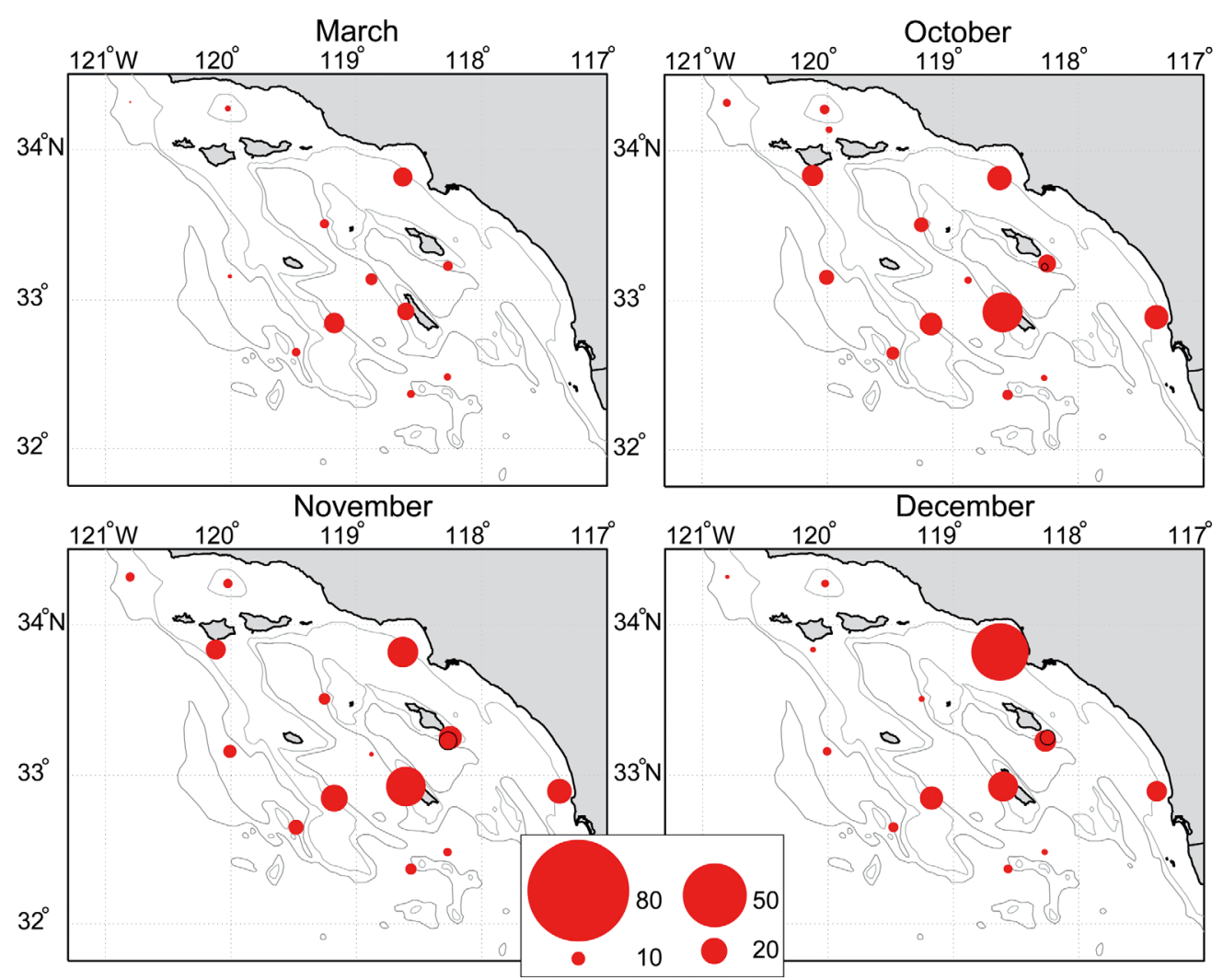

Fig. 9. Spatial distribution of calling fin whales Balaenoptera physalus based on the fin whale call index across the Southern California Bight during peak calling months. Size of the circle represents average daily value of fin whale call index for a given month at that site across all years with data, normalized by effort and transmission loss (TL)-area. Grey lines mark 500 and $1000 \mathrm{~m}$ bathymetry contours; smaller, black outlined circles denote additional data points with less calling presence than the neighboring site

of these 2 call types. In both studies (the present study and Oleson 2005), blue whale B calls peaked in late summer or early fall, although we found blue whale calls persisted later into December and January. That difference could be the result of the increased spatial coverage we had in the present study, or it could be an indicator of a prolonged residence time for blue whales in this area. Also, Oleson (2005) showed an earlier peak in fin whale calling presence, but that discrepancy may be the result of a difference in methodologies. Call counting during peak fin whale presence may result in underestimation of call abundance as other fin whale calls can create a band of noise that makes it difficult to detect individual calls. In such cases, acoustic energy provides a better metric for determining relative abundance of calling (Watkins et al. 2000, Širović et al. 2004). In general, however, year-round presence of fin whales has persisted since the Oleson (2005) study. Interestingly, the increase in the call index in the fall and winter is coincident with the longest inter-pulse interval (IPI) in the fin whale song (Ole- son et al. 2014). An increase in IPI would lead to a decrease in the fin whale call index; thus, if the song type described by Oleson et al. (2014) is dominant in the $\mathrm{SCB}$, seasonal increase in the fin whale call index cannot be explained by the change in the IPI, but must be caused by an increase in the total number of calls produced.

The overall seasonal pattern of blue and fin whale calling in the SCB is only slightly different from the seasonality observed farther north across the Pacific Ocean (Watkins et al. 2000, Stafford et al. 2009). In general, both blue and fin whale calls seem to peak a little earlier in the SCB, in early to late fall, respectively, while they persist across the North Pacific during the fall and into winter (Watkins et al. 2000). Interestingly, however, presence of fin whale calls during the spring was either greatly reduced (Stafford et al. 2009) or seemingly absent (Watkins et al. 2000) in the areas of the North Pacific closest to the SCB. Likewise, the timing of the blue whale call detection minimum was slightly different, as it occurred in June in the North Pacific, with calls fairly 


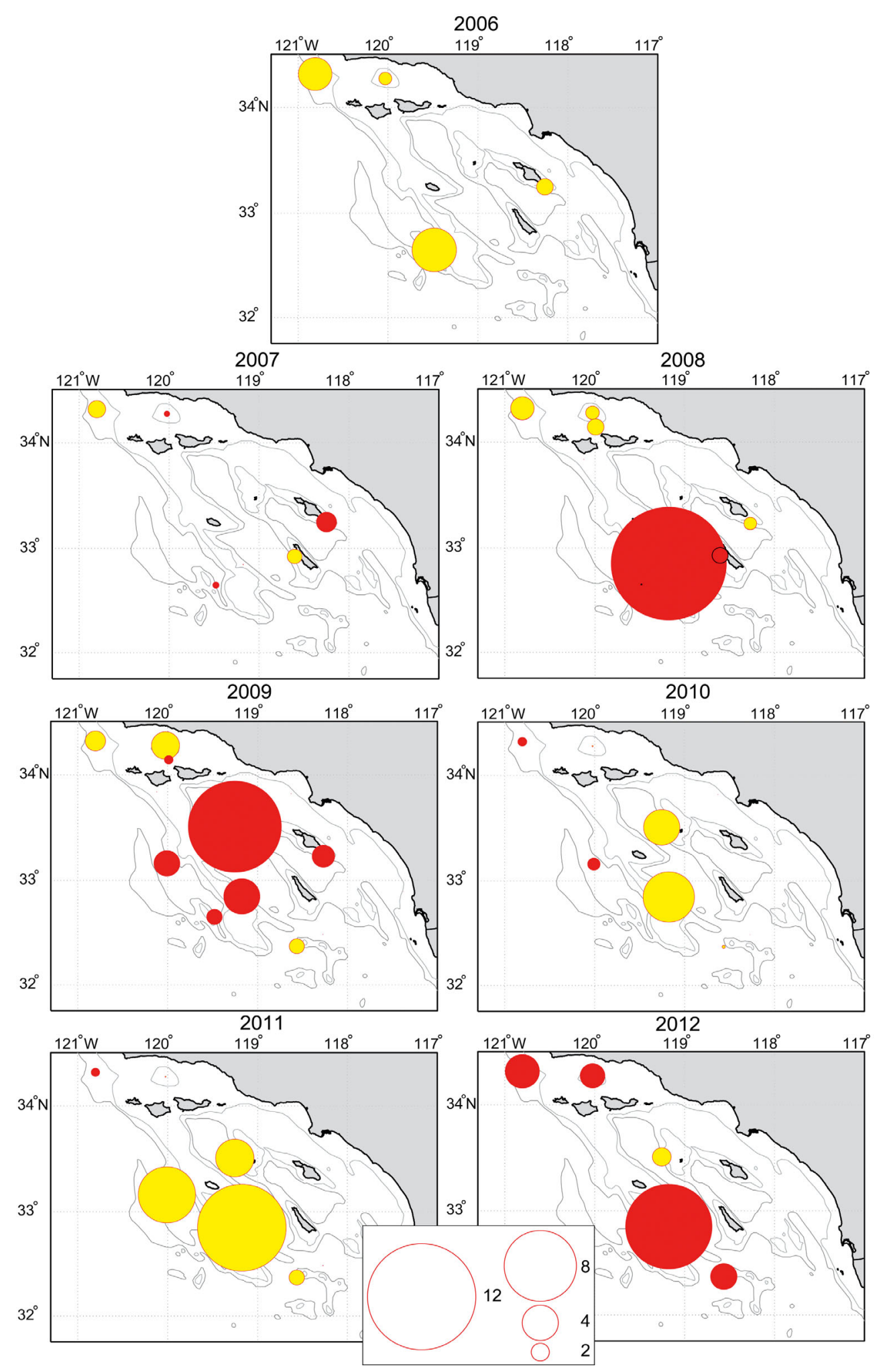

Fig. 10. Variation in the spatial distribution of fin whale (Balaenoptera physalus) call index across years in the Southern California Bight. Size of the circle represents the mean annual difference from the appropriate monthly average Southern California fin whale call index during this study. Yellow circles represent years with lower than average call index and red higher than average. All values are normalized by effort and transmission loss (TL)-area. Grey lines mark 500 and 1000 m bathymetry contours; smaller, black outlined circle denotes additional data point with less calling presence than the neighboring site. 
common in winter and spring (Watkins et al. 2000, Stafford et al. 2009), while our minimum occurred in the spring from March to May. Even though these data are not concurrent - the records from the North Pacific cover 1996 to 2002, while our data start in 2006 - they may offer insights into the general seasonal movement patterns of these 2 species across the northeast Pacific Ocean. It is possible that some blue whales, as they leave the SCB at the start of winter, may remain in the North Pacific rather than head south to the Eastern Tropical Pacific. It is also possible that there is some exchange between fin whales in the SCB and farther offshore in the North Pacific during the spring, as the calling is low or absent offshore in mid-summer and until October, when it has already started to pick up in the SCB.

\section{Data biases}

In the present study, we are using calling as a proxy for whale presence, but a number of biases are inherently present in this type of data. A built-in bias in any passive acoustic monitoring analysis is that calls are an indicator of animal presence, but when calls are absent, animal absence cannot be assumed. Finally, if the species has a complex calling repertoire, it is possible that it may be engaged in a different calling behavior and is not producing the type of call being monitored.

In the case of blue whales, we were only detecting B calls, which are thought to be associated with males and related to breeding (Oleson et al. 2007a). Hence seasonal peak in the summer and fall is likely a better indicator of that behavioral context, rather than a true indicator of absolute peak in blue whale presence in the SCB. As blue whales tend to produce B calls in long repetitive sequences, or songs, during that time of the year, this will yield more call detections than when they are just producing individual calls (Oleson et al. 2007b), and thus is not necessarily an indication of an increased number of blue whales. Additionally, low levels of calling earlier in the season, during spring and early summer, could mean that the animals are not yet ready for breeding but are engaging in different behaviors and are possibly producing other (D) calls (Oleson et al. 2007b).

For fin whales, call index has the same inherent bias, as the index will be higher when whales are producing long repetitive sequences of calls than when they are producing irregular calls or are engaged in callcounter call. However, call index has an advantage over individual call counting for fin whales in that it more accurately reflects the period of peak calling (Širović et al. 2004). As is the case for blue whales, fin whales also produce multiple calls, likely under different behavioral contexts (Watkins et al. 1987, Širović et al. 2013). Thus, the decrease in calling in the spring is likely an indicator of a different behavioral state, as we know that fin whales remain in this area year-round (Forney \& Barlow 1998, Širović et al. 2013). At this point, it was not feasible to include additional calls, such as $\mathrm{D}$ and $40 \mathrm{~Hz}$ calls, in this analysis as there are currently no automatic detectors that function effectively across a wide range of environmental conditions for these calls. Once successful automatic detectors are developed, expanding this study to the full calling repertoire of these species would be beneficial. However, we have shown that using even one call type per species allows monitoring of long-term trends and enables us to learn about the species' spatial use of the SCB.

Normalizing the call detections by detection area allowed direct comparison across sites, but at the same time, this process required a number of assumptions to be made, and thus introduced additional biases in the data. While a thorough investigation of all the possible biases that are introduced through this process is well beyond the scope of this paper (see Helble et al. 2013a,b), we tested some potential impact of those biases for 2 sites, G, a landassociated site, and $\mathrm{N}$, an open ocean site. For example, one of the assumptions we made was the source level of the call. Even though there can be variability in the call source levels (Watkins et al. 1987, McDonald et al. 2001, Weirathmueller et al. 2013), for the purposes of implementation, we had to choose one number and used average reported source level from a study. In the case of blue whales, however, assuming variability in calls from 180 to $190 \mathrm{~dB}$ (McDonald et al. 2001), the detection range could vary by $7-23 \%$ and detection area by $2-5 \%$. For fin whales, since the reported range of source levels is much larger, from 160 to $195 \mathrm{~dB}$ (Watkins et al. 1987, Weirathmueller et al. 2013), the possible impact of this variation is much larger as well, $8-62 \%$ for detection range and $1-58 \%$ for detection area.

Background noise also introduces a bias in the data (Helble et al. 2013a). In our cases, we tested for variability of -5 to $+10 \mathrm{~dB}$ from the average used, the range found in the basins of Southern California (McDonald et al. 2008). We found that noise could affect detection range by $8-23 \%$ for blue whales and $7-22 \%$ for fin whales. The detection area varied by $2-11 \%$ for blue whales and $1-12 \%$ for fin whales under different noise assumptions. Additional assump- 
tions that would need to be tested include whale calling depth, as well as a number of environmental factors that are included in ESME Workbench, including temporal and fine-scale resolution in the sound speed profile, and a finer-scale resolution of bottom composition and bathymetry. Unfortunately, implementing a normalization process that would take into account all the variability in actual time is still well beyond the computational power of today's personal computers. However, by developing a standard normalization scheme and applying it across 16 locations, we were able to perform inter-site comparisons that accounted for some of the site-specific features (especially bathymetry and overall noise level) and revealed differences in inter-site calling abundance that more accurately account for detectability than most previous studies have attempted.

\section{Potential causes of interannual variation}

Interannual changes could indicate a difference in the number of animals, or they could be due to a change in call rates. In the case of the latter, this would imply that fin whale call rates are increasing over long time scales. However, the pattern does not reveal a uniform or linear trend across the years; thus, the animals would also have to be changing their calling rate non-linearly. Currently, there is no published information on the long-term, interannual consistency of fin whale call rates. If the animals are not changing their call rates, alternative explanations are that they are distributing themselves differently in the SCB relative to the 3 sites we used for the long-term trend analysis, or that their numbers are in fact changing.

A likely explanation of the year-to-year variability in call detections and SCB use by these 2 species could lie in environmental changes. For example, the changes reported here could be related to large-scale climate oscillation patterns, such as the El Niño Southern Oscillation (ENSO). However, during 2008 versus 2007, when the overall abundances of calls were very different (high and low, respectively) for blue whales, the multivariate ENSO index was in the same phase (Wolter 2014). So to explain this interannual variability, an investigation into the trends in local habitat, at a much finer scale than is offered by large-scale climate patterns, is required. This analysis could include, for example, modeling of whale calling presence in relation to the environmental factors in the SCB, such as the variability in the sea surface temperature, as well as chlorophyll and zooplankton abundance, during the period from 2006 to 2012 .
Beyond the actual presence of calling animals, environmental factors can also affect the detectability of a call and thus influence our results. As demonstrated in the 'Data biases' section above, variation in background noise from shipping or other sources can affect the overall detection range (see also Simard et al. 2008, Helble et al. 2013b). This variability could be occurring over very short time scales, e.g. with each passage of a ship. Since we were investigating daily and monthly trends and changes, we did not try to account for this very fine-scale variability. However, by using site-specific noise characteristics in our propagation modeling, we believe we accounted for the long time-scale variability among sites and thus provide consistent and comparable values to evaluate across sites.

As a case in point, in 2008, California Air Resources Board passed a rule that required ships passing within 24 nautical miles of the California coast to use cleaner burning fuels starting in July 2009 (CARB 2008). This resulted in a temporary shift of some shipping out of the main shipping route in the Santa Barbara Channel to the south (McKenna et al. 2012). If this change had a large impact on our detection range, particularly at sites around the northern Channel Islands, we would have expected to see an increase in the number of blue whale B calls and fin whale call index within the channel, while we would have expected lower levels south of the northern Channel Islands starting from 2009. However, the opposite was true, as blue whale detections within the channel peaked in 2008, before the new rule took effect, and some of the highest levels of fin whale calls were detected south of the northern Channel Islands in 2009. Thus the observed interannual difference probably cannot be accounted for simply via changes in the shipping in this area.

Variable detectability could also result from behavioral changes in the calling animals, such as a shortterm change in call rates due to noise or other reasons (Parks et al. 2007, Helble et al. 2013b), or variable calling depth (Simard et al. 2008). There was no obvious evidence for a relationship between call rates and background noise in our data, as sites with, for example, high blue whale detections were found during both low and high average noise levels. A more detailed analysis would be needed to evaluate whether blue or fin whales actually change their call rate or source levels in response to background noise level; however, such a study is beyond the scope of this work. Scant information is available on the calling depth of these animals (Oleson et al. 2007a), so likewise, we cannot evaluate the likelihood that the 
whales are systematically changing their calling depth over time or from year to year, and thus systemically impacting our detection range. Further studies focusing on the tagging of calling blue and fin whales will help answer the question of whether change in call depth could explain some of the temporal variability observed in our study.

As illustrated here, passive acoustic methods are a valuable and effective tool for elucidating longterm spatial and temporal patterns in abundance and habitat use by endangered blue and fin whales. By analyzing nearly 26 instrument-years of data and detecting over 3 million blue whale calls, we were able to provide the most fine-scale qualitative descriptions of blue and fin whale use of the SCB to date. This knowledge alone should be valuable for future management of these endangered species in this heavily used region, but to further enhance our understanding of the trends presented here, it will be important to study potential drivers behind the seasonal and interannual variation described. This will be best accomplished by coupling these long-term records with fine-scale changes in the environment. This will allow us to further increase our knowledge of these endangered species in the SCB and ultimately provide a better baseline for studies on potential anthropogenic impacts of the plethora of human activities in the SCB on these species.

Acknowledgements. HARP deployment and recovery, and data processing and analysis were supported by Hannah Bassett, Sophie Brandstetter, Tim Christianson, Chris Garsha, Ryan Griswold, Brent Hurley, John Hurwitz, Sara Kerosky, Erin O'Neill, and Bruce Thayre. The analysis presented was based upon work supported by the Office of Naval Research (ONR) under award no. N00014-12-1-0904 (Michael Weise). Data collection was supported by the Chief of Naval Operations CNO-N45 (Frank Stone, Ernie Young and Bob Gisiner), the US Pacific Fleet (Chip Johnson), and the NOAA Channel Islands National Marine Sanctuary (RV 'Shearwater'). Portions of this work were made possible due to the National Oceanographic Partnership Program Award N00014-11-1-0697 (Michael Weise, ONR; and Jill Lewandowski and Jim Price, Bureau of Ocean Energy Management [BOEM]).

\section{LITERATURE CITED}

Bailey H, Mate BR, Palacios DM, Irvine L, Bograd SJ, Costa DP (2009) Behavioural estimation of blue whale movements in the Northeast Pacific from state-space model analysis of satellite tracks. Endang Species Res 10: 93-106

Barlow J (1995) The abundance of cetaceans in California waters. Part I: Ship surveys in summer and fall of 1991. Fish Bull 93:1-14
Barlow J, Forney KA (2007) Abundance and population density of cetaceans in the California Current ecosystem. Fish Bull 105:509-526

Barlow J, Taylor BL (2005) Estimates of sperm whale abundance in the northeastern temperate Pacific from a combined acoustic and visual survey. Mar Mamm Sci 21: 429-445

> Becker EA, Forney KA, Ferguson MC, Foley DG, Smith RC, Barlow J, Redfern JV (2010) Comparing California Current cetacean-habitat models developed using in situ and remotely sensed sea surface temperature data. Mar Ecol Prog Ser 413:163-183

Burtenshaw JC, Oleson EM, Hildebrand JA, McDonald MA, Andrew RK, Howe BM, Mercer JA (2004) Acoustic and satellite remote sensing of blue whale seasonality and habitat in the Northeast Pacific. Deep-Sea Res II 51: 967-986

Campbell GS, Thomas L, Whitaker K, Douglas A, Calambokidis J, Hildebrand JA (2015) Inter-annual and seasonal trends in cetacean distribution, density and abundance in waters off southern California. Deep-Sea Res II 112:143-157

CARB (California Air Resources Board) (2008) Supplemental environmental analysis of potential impactsfrom changes in southern California vessel routing as a result of the ARB ocean-going vessel fuel rule. Available at www.arb. ca.gov/ports/marinevess/ogv.htm (accessed 21 May 2014)

Cole T, Hartley D, Garron M (2006) Mortality and serious injury determinations for baleen whale stocks along the eastern seaboard of the United States, 2000-2004. Northeast Fisheries Science Center Reference Document 0604, Northeast Fisheries Science Center, Woods Hole, MA

Croll DA, Clark CW, Acevedo A, Tershy BR, Flores S, Gedamke J, Urban J (2002) Only male fin whales sing loud songs. Nature 417:809

Douglas AB, Havron AM, Calambokidis J, Camacho DL and others (2014) Seasonal distribution and abundance of cetaceans off Southern California estimated from CalCOFI cruise data from 2004 to 2008. Fish Bull 112:197-220

> Fiedler PC, Reilly SB, Hewitt RP, Demer D and others (1998) Blue whale habitat and prey in the California Channel Islands. Deep-Sea Res II 45:1781-1801

> Forney KA, Barlow J (1998) Seasonal patterns in the abundance and distribution of California cetaceans, 19911992. Mar Mamm Sci 14:460-489

Forney KA, Barlow J, Carretta JV (1995) The abundance of cetaceans in California waters. Part II: Aerial surveys in winter and spring of 1991 and 1992. Fish Bull 93:15-26

Helble TA, D'Spain GL, Campbell GS, Hildebrand JA (2013a) Calibrating passive acoustic monitoring: correcting humpback whale call detections for site-specific and time-dependent environmental characteristics. J Acoust Soc Am 134:EL400-EL406

Helble TA, D'Spain GL, Hildebrand JA, Campbell GS, Campbell RL, Heaney KD (2013b) Site specific probability of passive acoustic detection of humpback whale calls from single fixed hydrophones. J Acoust Soc Am 134:2556-2570

Irvine LM, Mate BR, Winsor MH, Palacios DM, Bograd SJ, Costa DP, Bailey H (2014) Spatial and temporal occurrence of blue whales off the US West Coast, with implications for management. PLoS ONE 9:e102959

Kawamura A (1980) A review of food of balaenopterid whales. Sci Rep Whales Res Inst 32:155-197

Marques TA, Thomas L, Ward J, DiMarzio N, Tyack PL (2009) Estimating cetacean population density using 
fixed passive acoustic sensors: an example with Blainville's beaked whales. J Acoust Soc Am 125:1982-1994

McDonald MA, Calambokidis J, Teranishi AM, Hildebrand JA (2001) The acoustic calls of blue whales off California with gender data. J Acoust Soc Am 109:1728-1735

McDonald MA, Mesnick SL, Hildebrand JA (2006) Biogeographic characterisation of blue whale song worldwide: using song to identify populations. J Cetacean Res Manag 8:55-65

> McDonald MA, Hildebrand JA, Wiggins SM, Ross D (2008) A 50 year comparison of ambient ocean noise near San Clemente Island: a bathymetrically complex coastal region off Southern California. J Acoust Soc Am 124:1985-1992

McDonald MA, Hildebrand JA, Mesnick S (2009) Worldwide decline in tonal frequencies of blue whale songs. Endang Species Res 9:13-21

McKenna MF, Katz SL, Wiggins SM, Ross D, Hildebrand JA (2012) A quieting ocean: unintended consequence of a fluctuating economy. J Acoust Soc Am 132:EL169-EL175

Melcón ML, Cummins AJ, Kerosky SM, Roche LK, Wiggins SM, Hildebrand JA (2012) Blue whales respond to anthropogenic noise. PLoS ONE 7:e32681

Mellinger DK, Clark CW (2000) Recognizing transient lowfrequency whale sounds by spectrogram correlation. J Acoust Soc Am 107:3518-3529

Nieukirk SL, Mellinger DK, Moore SE, Klinck K, Dziak RP, Goslin J (2012) Sounds from airguns and fin whales recorded in the mid-Atlantic Ocean, 1999-2009. J Acoust Soc Am 131:1102-1112

Oleson EM (2005) Calling behavior of blue and fin whales off California. PhD thesis, University of California San Diego, La Jolla, CA

> Oleson EM, Calambokidis J, Burgess WC, McDonald MA, LeDuc CA, Hildebrand JA (2007a) Behavioral context of call production by eastern North Pacific blue whales. Mar Ecol Prog Ser 330:269-284

> Oleson EM, Wiggins S, Hildebrand JA (2007b) Temporal separation of blue whale call types on a southern California feeding ground. Anim Behav 74:881-894

Oleson EM, Sirović A, Bayless AR, Hildebrand JA (2014) Synchronous seasonal change in fin whale song in the North Pacific. PLoS ONE 9:e115678

Pace RM III, Cole TVN, Henry AG (2014) Incremental fishing gear modifications fail to significantly reduce large whale serious injury rates. Endang Species Res 26: 115-126

Parks SE, Clark CW, Tyack PL (2007) Short- and long-term changes in right whale calling behavior: The potential effects of noise on acoustic communication. J Acoust Soc Am 122:3725-3731

Redfern JV, McKenna MF, Moore TJ, Calambokidis J and others (2013) Assessing the risk of ships striking large whales in marine spatial planning. Conserv Biol 27: 292-302

Reilly SB, Bannister JL, Best PB, Brown M and others (2008) Balaenoptera musculus. The IUCN Red List of Threat-

Editorial responsibility: Michael Noad,

Gatton, Queensland, Australia ened Species. Version 2014.3. Available at www.iucn redlist.org/details/2477/0 (accessed 28 February 2015)

Reilly SB, Bannister JL, Best PB, Brown M and others (2013) Balaenoptera physalus. The IUCN Red List of Threatened Species. Version 2014.3. Available at www.iucn redlist.org/details/2478/0 (accessed 28 February 2015)

> Rivers JA (1997) Blue whale, Balaenoptera musculus, vocalizations from the waters off central California. Mar Mamm Sci 13:186-195

Roch MA, Baumann-Pickering S, Batchelor H, Hwang D and others (2013) Tethys: a workbench and database for passive acoustic metadata. Oceans 2013. IEEE, San Diego, CA

Simard Y, Roy N, Gervaise C (2008) Passive acoustic detection and localization of whales: effects of shipping noise in Saguenay-St. Lawrence Marine Park. J Acoust Soc Am 123:4109-4117

Širović A, Hildebrand JA, Wiggins SM, McDonald MA, Moore SE, Thiele D (2004) Seasonality of blue and fin whale calls and the influence of sea ice in the Western Antarctic Peninsula. Deep-Sea Res II 51:2327-2344

> Širović A, Williams LN, Kerosky SM, Wiggins SM, Hildebrand JA (2013) Temporal separation of two fin whale call types across the eastern North Pacific. Mar Biol 160: $47-57$

Smith PE, Eppley RW (1982) Primary production and the anchovy population in the Southern California Bight: comparison of time-series. Limnol Oceanogr 27:1-17

Stafford KM, Citta JJ, Moore SE, Daher MA, George JE (2009) Environmental correlates of blue and fin whale call detections in the North Pacific Ocean from 1997 to 2002. Mar Ecol Prog Ser 395:37-53

Thompson P, Findley LT, Cummings WC (1996) Underwater sounds of blue whales, Balaenoptera musculus, in the Gulf of California, Mexico. Mar Mamm Sci 12:288-293

Watkins WA (1981) Activities and underwater sounds of fin whales. Sci Rep Whales Res Inst 33:83-117

> Watkins WA, Tyack P, Moore KE, Bird JE (1987) The 20-Hz signal of finback whales (Balaenoptera physalus). J Acoust Soc Am 82:1901-1912

> Watkins WA, Daher MA, Reppucci GM, George JE, Martin DL, DiMarzio NA, Gannon DP (2000) Seasonality and distribution of whale calls in the North Pacific. Oceanography 13:62-67

> Weirathmueller MJ, Wilcock WSD, Soule DC (2013) Source levels of fin whale $20 \mathrm{~Hz}$ pulses measured in the Northeast Pacific Ocean. J Acoust Soc Am 133:741-749

Wiggins SM, Hildebrand JA (2007) High-frequency acoustic recording package (HARP) for broad-band, long-term marine mammal monitoring. Proc Int Symp Underwater Technology 2007 and Int Workshop on Scientific Use of Submarine Cables and Related Technologies. IEEE, Tokyo

Wolter K (2014) Multivariate ENSO Index (MEI). Available at www.esrl.noaa.gov/psd/enso/mei/ (accessed 21 May 2014)

Submitted: October 6, 2014; Accepted: March 31, 2014 Proofs received from author(s): June 16, 2015 